\title{
IMOBILIZAÇÃO DE BETA-GALACTOSIDASE UTILIZANDO A TÉCNICA CLEA (CROSS-LINKED ENZYME AGGREGATES)
}

\author{
L. G. ULRICH ${ }^{1}$, A. C. O. MAFRA ${ }^{2}$, P. W. TARDIOLI ${ }^{1,2}$ e M. P.A. RIBEIRO ${ }^{1,2}$ \\ ${ }^{1}$ Universidade Federal de São Carlos, Departamento de Engenharia Química \\ ${ }^{2}$ Pós-Graduação em Engenharia Química, Universidade Federal de São Carlos (PPG-EQ / \\ UFSCar) \\ E-mail para contato: marceloribeiro@ufscar.br
}

\begin{abstract}
RESUMO - Realizou-se a otimização da imobilização por agregados enzimáticos reticulados (Cross-Linked Enzyme Aggregates CLEAs) de $\beta$-galactosidase (EC 3.2.1.23) de Kluyveromyces lactis. A metodologia de preparo dos CLEAs consiste na precipitação da proteína e entrecruzamento com grupos amino reativos livres em sua superfície, via reação com um reagente bifuncional. Dessa forma, foram avaliados os rendimentos de imobilização de derivados preparados com diferentes agentes precipitantes (polietilenoglicol 400, álcool terc-butílico, acetona, dimetoxietano, etanol e sulfato de amônio), diferentes concentrações de agente entrecruzante $(0,0,3,0,6$ e $1 \mathrm{mM})$ e presença de proteína espaçadora soja nas proporções $\mathrm{mg}_{\mathrm{Soja}} / \mathrm{mg}_{\text {Enzima }} 2$ e 4 e mmol $_{\text {Gutaraldeído }} / \mathrm{g}_{\text {Proteína Total }} 2,2,5$ e 3 . O derivado que apresentou rendimento de imobilização máximo de $74,6 \%$ foi preparado utilizando álcool terc-butílico, glutaraldeído na razão $2 \mathrm{mmol}_{\mathrm{G}} / \mathrm{g}_{\text {Proteína }}$ Total e razão entre proteína espaçadora soja e enzima, respectivamente, 0,4 mg/0,2 mg.
\end{abstract}

\section{INTRODUÇÃO}

Os chamados agregados enzimáticos reticulados (Cross-linked Enzymes Aggregates CLEAs) são obtidos por meio da preparação e imobilização enzimáticas em um único passo. A metodologia consiste na precipitação da proteína e entrecruzamento com grupos amino reativos livres de lisina em sua superfície, via reação com um reagente bifuncional, tal como glutaraldeído (Sheldon, 2010). A metodologia CLEA, demonstrada pela Figura 1, é simples, amplamente aplicável, não requer uma enzima altamente purificada ou uma matriz sólida (Sheldon et al., 2013). O método pode, ainda, estabilizar as estruturas quaternárias de enzimas multiméricas (Wilson et al., 2004).

Figura 1 - Representação da preparação dos CLEAs. A enzima solúvel é agregada pela ação de um precipitante e, em seguida, ocorre o entrecruzamento dos agregados enzimáticos pela ação de um agente intercruzante. 


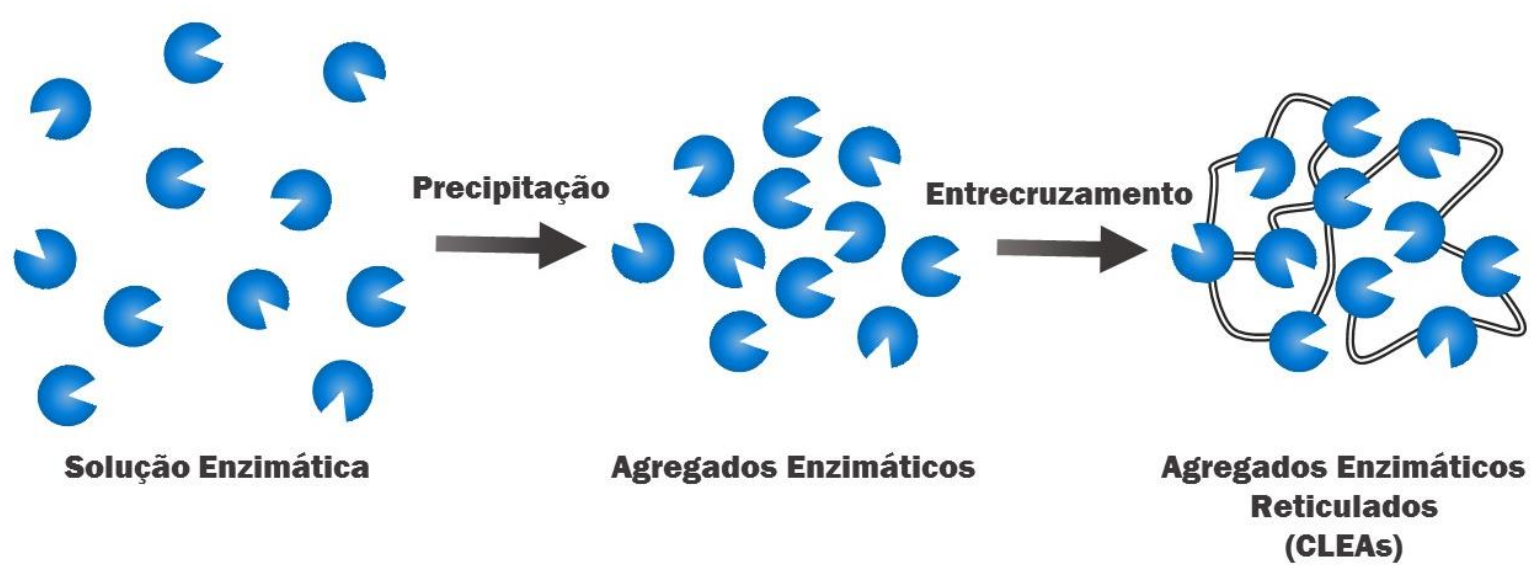

A levedura Kluyveromyces lactis é uma importante fonte comercial de $\beta$-galactosidase (EC.3.2.1.23) ( $\beta$-gal) (Rodriguez-Colinas et al., 2011), a qual é um tetrâmero de massa molecular de $119 \mathrm{kDa}$ (Pereira-Rodríguez et al., 2012). Essa enzima multimérica hidrolisa a lactose nos monômeros glicose e galactose e, também, pode ser utilizada na transgalactosilação da lactose, para sintetizar galacto-oligossacarídeos (GOS) (Panesar et al., 2010).

A $\beta$-gal imobilizada por CLEA foi reportada em várias obras da literatura (Schoevaart et al., 2004; Gaur et al., 2006; Sheldon, 2010; Li et al., 2015). Contudo, não foi avaliada a $\beta$-gal de $K$. lactis ou a adição de uma proteína espaçadora durante a imobilização, visando a diminuição da resistência à transferência de massa e o entrecruzamento excessivo. Portanto, neste trabalho, foram estudados CLEAs de $\beta$-gal de $K$. lactis. Os efeitos de diferentes agentes precipitantes e diferentes concentrações de agente entrecruzante e proteína espaçadora foram avaliados na atividade da enzima.

\section{MATERIAIS E MÉTODOS}

\subsection{Materiais}

Nos ensaios, foi utilizada a enzima comercial $\beta$-galactosidase (EC 3.2.1.23) de Kluyveromyces lactis (Lactozym 3000L), adquirida de Novozymes AS. Para a síntese e avaliação de $\beta$-galCLEAs foram empregados os reagentes polietilenoglicol 400 (PEG 400) (Synth, Brasil), álcool terc-butílico (TBA) (Vetec, Brasil), acetona (A) (Vetec, Brasil), dimetoxietano (DME) (Fluka), sulfato de amônio (AS) (Vetec, Brazil), etanol (92,8 $\mathrm{INMP}$ ) (adquirido de mercado local), glutaraldeído em solução aquosa 25\% (Vetec, Brazil), proteína de soja (Doremus ingredientes Brasil), lactose (Synth, Brasil) e Glicose Liquiform (Labtest, Brasil). Em todos os ensaios, foi utilizado o tampão fosfato de potássio com $\mathrm{pH} 7,0$, força iônica $50 \mathrm{mM}, \mathrm{NaCl} 10 \mathrm{mM}$ e $\mathrm{MgCl}_{2}$ 1,5 mM.

\subsection{Métodos}

Determinação da atividade enzimática: Foi utilizado o método da velocidade inicial (Rossetto et al., 2013). Adicionaram-se $20 \mathrm{~mL}$ de 100 g.L. $\mathrm{L}^{-1}$ lactose em tampão a um reator agitado e a $37^{\circ} \mathrm{C}$. Uma amostra inicial foi retirada e a solução enzimática foi adicionada. Amostras de $10 \mu \mathrm{L}$ foram retiradas em intervalos de tempo predefinidos e, com o tubo 
fechado, levadas à água fervente durante 1 minuto, para inativação da enzima. A determinação da concentração de glicose foi realizada pelo método GOD-PAP (Trinder, 1969). Uma unidade de atividade enzimática (U) foi definida como a quantidade de enzima necessária para produzir $1 \mu \mathrm{mol}$ de glucose por minuto, nas condições definidas.

Preparação de CLEAs de $\beta$-galactosidase: A preparação de CLEA seguiu o método descrito por Mafra et al. (2016). Adicionou-se lentamente o agente precipitante (polietilenoglicol 400 [PEG], álcool terc-butílico [TBA], acetona [A], dimetoxietano [DME], etanol [E] ou sulfato de amônio saturado [AS]) a $1 \mathrm{~mL}$ de $\beta$-gal (0,2 g.L. $\mathrm{L}^{-1}$ em tampão). Agitou-se um conjunto de tubos eppendorf $(2 \mathrm{~mL})$ em um agitador de vórtex durante $1 \mathrm{~min}$, adicionou-se lentamente glutaraldeído $(\mathrm{G})$ até à concentração final de $0,0,3,0,6$ ou $1 \mathrm{mM}$. Os tubos foram colocados em shaker para incubação durante $3 \mathrm{~h}$ a $\sim 10^{\circ} \mathrm{C}$ e $\sim 200 \mathrm{rpm}$. As suspensões de agregados foram centrifugadas a $12000 \mathrm{rpm}$ durante $10 \mathrm{~min}$ e a $10^{\circ} \mathrm{C}$. Os CLEAs de $\beta$-gal foram recuperados e lavados com tampão. Para a imobilização com proteína espaçadora, preparou-se uma solução enzimática dissolvendo $0,2 \mathrm{mg}$ de $\beta$-gal e $0,4 \mathrm{mg}$ ou 0,8 $\mathrm{mg}$ de soja em $1 \mathrm{~mL}$ de tampão (proporções $\mathrm{mg}_{\mathrm{Soja}} / \mathrm{mg}_{\text {Enzima }} 2$ ou 4). A concentração de glutaraldeído também foi avaliada na razão de $2,2,5$ ou $3 \mathrm{mmol}_{\mathrm{G}} / \mathrm{g}_{\text {Proteína Total. }}$.

Após a preparação, a enzima foi mantida no mesmo tampão $(2 \mathrm{~mL})$ a $4^{\circ} \mathrm{C}$ e a atividade de $\beta$-gal-CLEA foi medida como já descrito. O rendimento de imobilização (Y) foi calculado como se segue:

$$
Y(\%)=\frac{A_{e}}{A_{\text {i }}} \times 100
$$

Onde $A_{e}$ é a atividade total de $\beta$-gal em CLEAs; $A_{i}$ é a atividade total de $\beta$-gal utilizada para a produção de CLEAs.

\section{RESULTADOS E DISCUSSÃO}

Ao analisar a Figura 2A, verifica-se que a triagem de precipitantes apresentou um alto rendimento (Y) para TBA $(88,3 \%)$ e A $(93,5 \%)$ e baixo Y para AS $(3,1 \%)$. Li et al. (2015) obtiveram resultados diferentes ao avaliar AS, A e outros. Os resultados de ensaios de atividade obtidos por estes autores mostraram que AS (90\% de saturação) apresentou melhor recuperação da proteína precipitada, cerca de $92 \%$. Ao comparar os resultados obtidos por Li et al (2015) e os obtidos no presente trabalho, observa-se que há divergência entre eles, podendo ser explicada pela menor concentração empregada neste presente ensaio $(2,5 \mathrm{M}$ no frasco eppendorf), afetando a recuperação do precipitado. A diminuição de Y pode ser atribuída à perda de enzima no sobrenadante e à inativação enzimática devido ao agente precipitante.

Figura 2 - A) Y em triagem precipitante: AS, TBA, PEG, DME, A e E. B) Y em preparações de CLEAs: TBA e A, concentrações de $\mathrm{G}$ 0,3 mM, 0,6 mM e 1,0 mM. C) Y em preparações CLEAs com proteína espaçadora: TBA e A, Soja e G nas proporções: (2 e 4 $\left.\mathrm{mg}_{\text {Soja }} / \mathrm{mg}_{\text {Enzima }}\right) ;\left(2\right.$ a $\left.3 \mathrm{mmol}_{\mathrm{G}} / \mathrm{g}_{\text {Proteína Total }}\right)$. 

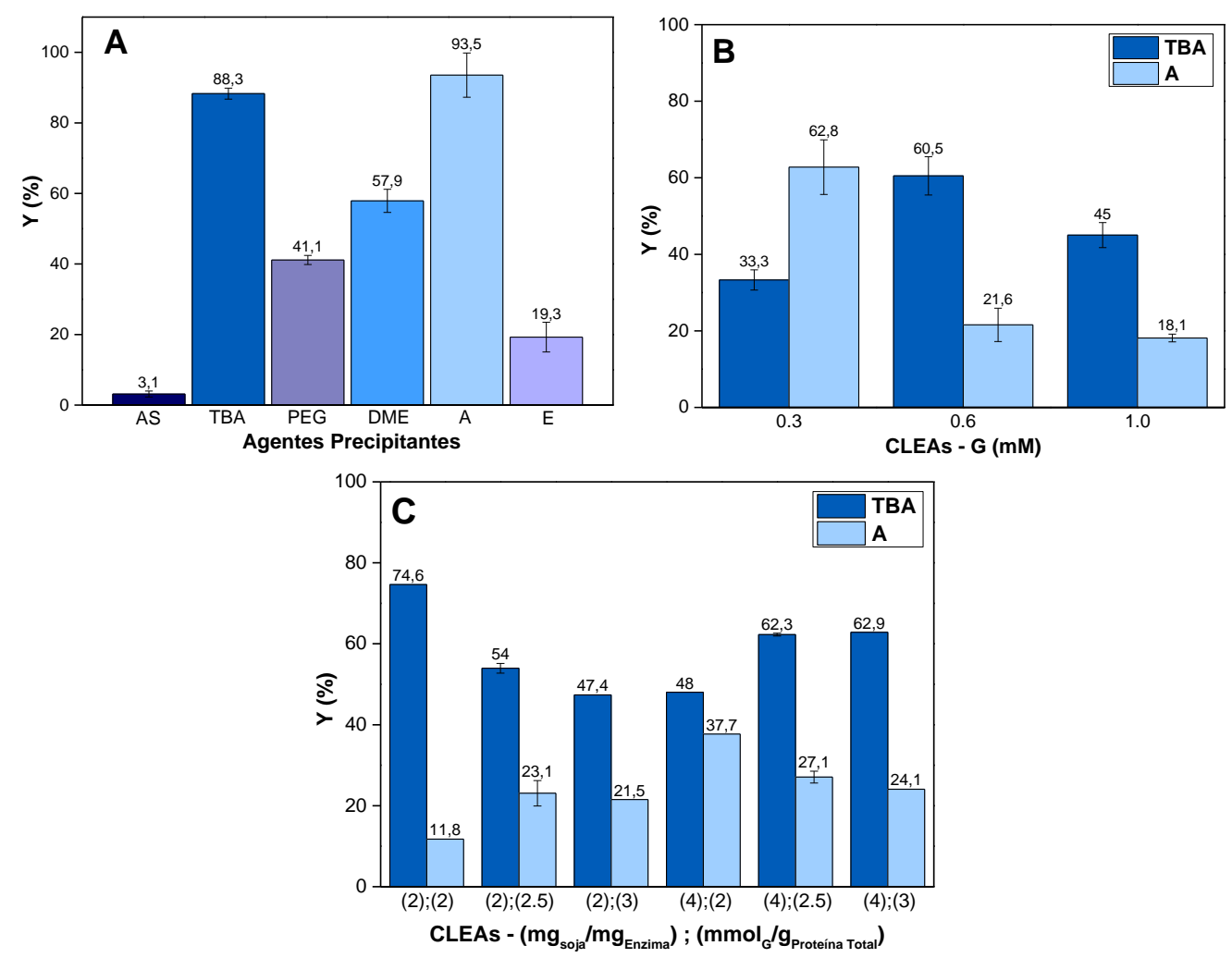

Prosseguiu-se, então, para a etapa de produção de CLEAs de $\beta$-galactosidase de Kluyveromyces lactis, com o uso dos precipitantes TBA ou A e de diferentes concentrações de G. CLEAs preparados com TBA (G 0,6 mM) e A (G 0,3 mM) apresentaram os melhores resultados, com valores respectivos de Y 60,5\% e 62,8\%, conforme Figura 2B). Vale ressaltar que Y destes CLEAs, após o primeiro passo de centrifugação, era de cerca de $92 \%$ (dado não mostrado). A diferença se deve à lixiviação de enzimas no meio no segundo passo de centrifugação. Gaur et al. (2006) obtiveram um rendimento de 13,5\% de atividade de CLEA a partir de A. oryzae $\beta$-gal numa preparação utilizando 100x mais enzima, AS (G 100Mm). Este resultado foi semelhante ao CLEA preparado neste trabalho com $A(G 0,1 \mathrm{mM})$ (Y de $18,1 \%)$.

O efeito da soja como proteína espaçadora na imobilização também foi investigado, como visto na Figura 2C). A proteína espaçadora BSA já foi utilizada para diluir outras enzimas na imobilização CLEA. Tükel et al. (2013) mostraram que a adição de BSA poderia aumentar o rendimento de CLEAs de catalase, o que pode ser uma evidência da redução da resistência difusional. A soja foi usada aqui como uma alternativa à BSA, visando menor custo do processo. Obteve-se a melhor recuperação $(74,6 \%)$ com CLEA preparado com TBA, nas razões $\mathrm{mg}_{\mathrm{Soja}} / \mathrm{mg}_{\text {Enzima }}$ de 2 e $\mathrm{mmol}_{\mathrm{G}} / \mathrm{g}_{\text {Proteína Total }}$ de $2(0,6 \mathrm{mM})$.

\section{CONCLUSÃO}

A enzima $\beta$-gal proveniente de Kluyveromyces lactis foi imobilizada utilizando a técnica de Cross-linked Enzymes Aggregates. Para obter uma metodologia otimizada do preparo de CLEAs, uma triagem de precipitantes inicial foi realizada, sendo TBA e A selecionados entre outros agentes precipitantes, por apresentarem derivados com maior rendimento $(88,3 \%$ e $93,5 \%)$. Em seguida, foram preparados CLEAs com tais precipitantes 
selecionados e diferentes concentrações de glutaraldeído. O rendimento de imobilização mostrou valores promissores ( 60\%) para CLEAs preparados com TBA $(\mathrm{G} \mathrm{0,6} \mathrm{mM)} \mathrm{e} \mathrm{A}(\mathrm{G}$ $0,3 \mathrm{mM})$. Ainda, foram sintetizados agregados enzimáticos reticulados na presença de proteína espaçadora. O melhor resultado de imobilização apresentado neste presente trabalho (rendimento de $74,6 \%$ ) foi obtido quando a proteína espaçadora Soja foi adicionada na preparação de CLEAs com TBA nas razões $\mathrm{mg}_{\mathrm{Soja}} / \mathrm{mg}_{\text {Enzima }}$ de 2 e mmol $\mathrm{G}_{\mathrm{G}} / \mathrm{g}_{\text {Proteína Total }}$ de 2.

\section{AGRADECIMENTOS}

Este trabalho foi apoiado pelo processo $n^{\circ}$ 2016/20330-3, Fundação de Amparo à Pesquisa do Estado de São Paulo (FAPESP). As opiniões, hipóteses e conclusões ou recomendações expressas neste material são de responsabilidade dos autores e não necessariamente refletem a visão da FAPESP. Os autores também agradecem à CAPES e ao CNPq (\# 141647 / 2013-2) pelas bolsas de pesquisa.

\section{REFERÊNCIAS BIBLIOGRÁFICAS}

GAUR, R.; PANT, H.; JAIN, R.; KHARE, S. K. Galacto-oligosaccharide synthesis by immobilized Aspergillus oryzae $\beta$-galactosidase. Food Chemistry, v. 97, p. 426-430, 2006.

LI, L.; LI, G.; CAO, L. C.; REN, G. H.; KONG, W.; WANG, S. D.; LIU, Y. H. Characterization of the cross-linked enzyme aggregates of a novel $\beta$-galactosidase, a potential catalyst for the synthesis of galacto-oligosaccharides. Journal of agricultural and food chemistry, v. 63, p. 894-901, 2015.

MAFRA, A. C. O.; KOPP, W.; BELTRAME, M. B.; GIORDANO, R. D. L. C.; DE ARRUDA RIBEIRO, M. P.; TARDIOLI, P. W. Diffusion effects of bovine serum albumin on cross-linked aggregates of catalase. Journal of Molecular Catalysis B: Enzymatic, v. 133, p. 107-116, 2016.

PANESAR, P. S.; KUMARI, S.; PANESAR, R. Potential applications of immobilized $\beta$-galactosidase in food processing industries. Enzyme Research, v. 2010, 2010.

PEREIRA-RODRÍGUEZ, Á.; FERNÁNDEZ-LEIRO, R.; GONZÁLEZ-SISO, M. I.; CERDÁN, M. E.; BECERRA, M.; SANZ APARICIO, J. Structural basis of specificity in tetrameric Kluyveromyces lactis $\beta$-galactosidase. Journal of structural biology, v. 177, p. 392-401, 2012.

RODRIGUEZ-COLINAS, B.; DE ABREU, M. A.; FERNANDEZ-ARROJO, L.; DE BEER, R.; POVEDA, A.; JIMENEZ-BARBERO, J.; PLOU, F J. Production of galactooligosaccharides by the $\beta$-galactosidase from Kluyveromyces lactis: Comparative analysis of permeabilized cells versus soluble enzyme. Journal of agricultural and food chemistry, v. 59, p. 10477-10484, 2011.

ROSSETTO, B. P.; ZANIN, G. M.; DE MORAES, F. F. Determinação da Atividade da Enzima B-galactosidase por Lactose do Soro de Queijo. BBR-Biochemistry and Biotechnology Reports, v. 1, p. 28-32, 2013. 
SCHOEVAART, R.; WOLBERS, M. W.; GOLUBOVIC, M.; OTTENS, M.; KIEBOOM, A. P. G.; VAN RANTWIJK, F.; SHELDON, R. A. Preparation, optimization, and structures of cross-linked enzyme aggregates (CLEAs). Biotechnology and Bioengineering, v. 87, p. 754-762, 2004.

SHELDON, R. A. Cross-linked enzyme aggregates as industrial biocatalysts. Organic Process Research \& Development, v. 15, p. 213-223, 2010.

SHELDON, R. A., VAN PELT, S. Enzyme immobilization in biocatalysis: why, what and how. Chemical Society Reviews, v. 42, p. 6223-6235, 2013.

TRINDER, P. Determination of glucose in blood using glucose oxidase with an alternative oxygen acceptor. Annals of clinical Biochemistry, v. 6, p. 24-27, 1969.

TÜKEL, S. S.; HÜRREM, F.; YILDIRIM, D.; ALPTEKIN, Ö. Preparation of crosslinked enzyme aggregates (CLEA) of catalase and its characterization. Journal of Molecular Catalysis B: Enzymatic, v. 97, p. 252-257, 2013.

WILSON, L.; BETANCOR, L.; FERNÁNDEZ-LORENTE， G.; FUENTES， M.; HIDALGO, A.; GUISÁN, J. M.; FERNÁNDEZ-LAFUENTE, R. Cross-linked aggregates of multimeric enzymes: a simple and efficient methodology to stabilize their quaternary structure. Biomacromolecules, v. 5, p. 814-817, 2004. 